\title{
Isolation and molecular characterization of Clostridium perfringens from healthy Merino lambs in Patagonia region, Argentina
}

Mignaqui, A. C.; Marcellino, R. B.; Ronco, Troels; Pappalardo, J. S.; Nonnemann, Bettina; Pedersen, Karl; Robles, C. A.

\section{Published in:}

Anaerobe

Link to article, DOI:

10.1016/j.anaerobe.2016.10.015

Publication date:

2017

Document Version

Peer reviewed version

Link back to DTU Orbit

Citation $(A P A)$ :

Mignaqui, A. C., Marcellino, R. B., Ronco, T., Pappalardo, J. S., Nonnemann, B., Pedersen, K., \& Robles, C. A. (2017). Isolation and molecular characterization of Clostridium perfringens from healthy Merino lambs in Patagonia region, Argentina. Anaerobe, 43, 35-38. https://doi.org/10.1016/j.anaerobe.2016.10.015

\section{General rights}

Copyright and moral rights for the publications made accessible in the public portal are retained by the authors and/or other copyright owners and it is a condition of accessing publications that users recognise and abide by the legal requirements associated with these rights.

- Users may download and print one copy of any publication from the public portal for the purpose of private study or research.

- You may not further distribute the material or use it for any profit-making activity or commercial gain

- You may freely distribute the URL identifying the publication in the public portal 
1 Isolation and molecular characterization of Clostridium perfringens from healthy Merino

2 lambs in Patagonia Region, Argentina

3 Mignaqui, $\mathrm{AC}^{\mathrm{a}^{*}} ;$ Marcellino, $\mathrm{RB}^{\mathrm{b}}$; Ronco $\mathrm{T}^{\mathrm{c}}$; Pappalardo, $\mathrm{JS}^{\mathrm{b}}$; Nonnemann, $\mathrm{B}^{\mathrm{c}}$; Pedersen,

$4 \quad \mathrm{~K}^{\mathrm{c}}$; Robles, $\mathrm{CA}^{\mathrm{b}}$

$5 \quad{ }^{a}$ National Institute for Agricultural Technology, Bariloche Research Station, CONICET, Bote

6 Modesta Victoria 4450, San Carlos de Bariloche (R8403DVZ), Río Negro, Argentina.

$7 \quad{ }^{\mathrm{b}}$ National Institute for Agricultural Technology, Bariloche Research Station, Bote Modesta

8 Victoria 4450, San Carlos de Bariloche (R8403DVZ), Río Negro, Argentina.

$9{ }^{\mathrm{c}}$ Technical University of Denmark, National Veterinary Institute, Bülowsvej 27 (1870),

10 Frederiksberg, Denmark

11 *Corresponding author at: E-mail address: mignaqui.anaclara@inta.gob.ar, tel.: (+54 294)

12 4422731; fax: (+54 294) 4424991.

13 Keywords: Clostridium perfringens; lambs; enterotoxaemia; PCR; PFGE. 


\section{Abstract:}

The presence and molecular characterization of Clostridium perfringens in healthy Merino lambs over a six-month period was investigated in this study. Overall, a high prevalence of C. perfringens was detected, even in day-old lambs. Even though the majority of the isolates were characterized as being of type A, types C and D were also isolated. Furthermore, a high genetic diversity was observed by PFGE among the type A isolates.

Clostridium perfringens is an anaerobic, Gram-positive bacterium that can be found in the in the gastrointestinal tract of healthy humans and animals [1,2]. Under certain circumstances, $C$. perfringens is able to cause severe diseases by the production of a variety of toxins [3]. Depending on the ability to produce four of these toxins (alpha, beta, epsilon, iota), C. perfringens strains are classified into five types (A, B, C, D, E) [4]. All C. perfringens types harbor the alpha toxin-encoding gene (cpa) and in the case of type A strains only the cpa gene is carried. C. perfringens types B and C also harbor the beta toxin gene $(c p b)$ and additionally types B and D strains carry the epsilon toxin gene (etx), whereas type E strains carry the iota toxin gene ( $i A)$. Besides these classifying toxins, all types of $C$. perfringens can produce other toxins involved in the pathogenic behavior of the bacterium; such as the enterotoxin (cpe), the beta2 toxin (cpb2) and the NetB toxin $(n e t B)$ [5-7].

In sheep, all $C$. perfringens types can produce gastrointestinal diseases [8,9]. Among the different $C$. perfringens types, type A is the most common type isolated from the intestine of healthy domestic animals and in the environment. However, it is also able to cause 
gastrointestinal disease in lambs known as yellow lamb dysentery [10-12]. C. perfringens type $B$ is responsible of dysentery and type $C$ of necrotic enteritis [8]. Both diseases occur mainly in newborn lambs during the first days of life and beta toxin is responsible for the characteristic lesions. Enterotoxaemia is caused by type D strains that produce the epsilon toxin and is one of the most common clostridial diseases in sheep [8].

Diseases caused by $C$. perfringens are triggered by different predisposing factors, such as stress situations or sudden changes in diet, that allow proliferation of the bacterium and production of toxins $[8,13]$.

Prevalence studies in healthy lambs and lambs with clostridial gastrointestinal diseases have reported the presence of $C$. perfringens types A, B, C and D [10,11,14]. However, data from longitudinal studies is not available. In order to better understand the behavior of this complex pathogen in lambs, we analyzed the presence and molecular characterization of $C$. perfringens isolates collected from healthy lambs during a six-month period.

The study was conducted at INTA's Experimental Farm (S41 $1^{\prime} 55^{\prime \prime}$ W70 $\left.35{ }^{\prime 2} 24^{\prime \prime}\right)$ located at Patagonia, Argentina; from October 2014, when the lambing season started, to May 2015. Fifteen healthy female Merino lambs belonging to the same flock, born within six days from 31 October to 5 November 2014, were used in this study (Table 1). Samples were collected during six months starting from the day the lambs were born. The age of the animals at each sampling time is found in Table 1.

Samples were obtained from lambs using a sterile swab that was inserted 3 to $4 \mathrm{~cm}$ into the rectum and gently rotated and rubbed against the inner wall of the rectum. Fecal swabs 
were then transported to the laboratory in sterile screw-capped tubes containing $5 \mathrm{ml}$ of glycerol $50 \% \mathrm{v} / \mathrm{v}$ in saline solution at room temperature and were processed the same day.

Fecal swabs were inoculated into Tarozzi broth medium and incubated in anaerobic jars (Oxoid, United Kindom) in an atmosphere with $\mathrm{H}_{2} 80 \%$ and $\mathrm{CO}_{2} 20 \%$ at $37^{\circ} \mathrm{C}$ for $24 \mathrm{~h} \mathrm{[1]}$. Subsequently, blood agar (BA) plates (Britania, Argentina) were spread plated with $0.1 \mathrm{ml}$ of the cultivated Tarozzi broth medium and incubated anaerobically. After incubation, colonies compatible with $C$. perfringens (medium-sized, bright, round, with a characteristic double-zone haemolysis) were subcultured in thioglycolate medium (Britania, Argentina). Gram staining and biochemical tests (production of catalase, lecithinase, reverse CAMP and aerotolerance) were carried out to identify the isolates [15].

Some $C$. perfringens isolates were further analyzed by Matrix-assisted laser desorption/ionization time of flight mass spectrometry (MALDI TOF). All the isolates analyzed by MALDI TOF were demonstrated to be $C$. perfringens with a high score value confirming the correct identification by classical bacteriological means (data not shown).

DNA was extracted from Tarozzi broth medium after $24 \mathrm{~h}$ of cultivation with fecal swabs and from pure thioglycolate cultures with $150 \mu 1$ of $5 \%$ Chelex resin (Bio-Rad, USA) following manufacturer's instructions.

Multiplex PCR targeting the $c p a, c p b$, etx, $i A, c p e$ and $c p b 2$ genes was performed using primers previously described [16,17]. Reactions contained a final concentration of $0.4 \mu \mathrm{M}$ of $c p a$ primers, $0.36 \mu \mathrm{M}$ of $c p b$ primers, $0.5 \mu \mathrm{M}$ of $e t x$, $i A$ and $c p b 2$ primers, $0.6 \mu \mathrm{M}$ cpe primers, $10 \mathrm{mM}$ of dNTPs, $2 \mathrm{mM} \mathrm{MgCl} 2,2 \times$ PCR buffer Taq Pegasus (PB-L, Argentina), 1.25 units of DNA Taq Pegasus, $1 \mu 1$ of template and water to $25 \mu 1$. The thermal cycling 
was carried out with 25 cycles of denaturation at $95^{\circ} \mathrm{C}$ for $1 \mathrm{~min}$, annealing at $53^{\circ} \mathrm{C}$ for 1 min, and extension at $72^{\circ} \mathrm{C}$ for $1 \mathrm{~min}$, finally an additional extension period of $10 \mathrm{~min}$ at 72 ${ }^{\circ} \mathrm{C}$ was done. PCR products were subject to electrophoresis in $2.2 \%$ agarose gel for $40 \mathrm{~min}$ at $100 \mathrm{~V}$ and stained with Gel Red (Biotium, USA). PCR product visualization and documentation were performed under $254 \mathrm{~nm}$ UV light.

Nineteen C. perfringens isolates were analyzed by Pulsed-Field Gel Electrophoresis (PFGE) as previously described [18]. Briefly, colonies from BA were picked and suspended in Brain Heart Infusion broth (Becton Dickinson, USA). Then, the cultures were centrifuged and washed with ice-cold PIV buffer before being embedded in agarose (BioRad, USA). Agarose blocks were lysed and then digested with $20 \mathrm{U}$ SmaI (Invitrogen, USA) for $3 \mathrm{~h}$ at $30^{\circ} \mathrm{C}$. The restricted fragments were separated in a $1 \%$ agarose gel in $0.5 \times$ TBE buffer by using a CHEF-DR III system (Bio-Rad). Following the electrophoresis, the gel was stained in aqueous ethidium bromide $2 \mu \mathrm{g} / \mathrm{ml}$ followed by a distained step in water and photographed under $254 \mathrm{~nm}$ UV light. The reference strain used for the analysis was Salmonella serotype Braenderup H9812 and was digested with XbaI (Invitrogen, USA) for $3 \mathrm{~h}$ at $37^{\circ} \mathrm{C}[19]$.

PFGE gel photos were imported to BioNumerics version 7.1 (Applied Maths, Belgium) as JPG files and bands were assigned to each lane. The similarity among the isolates was calculated using the Dice similarity coefficient with branch matching of $2 \%$ tolerance, and the cluster analysis was based on the unweighted pair-group method with arithmetic averages (UPGMA).

The results of the present study demonstrate a high prevalence of $C$. perfringens in healthy Merino lambs from Patagonia, Argentina. C. perfringens was isolated at all sampling times, 
at least from one animal throughout a six-month period (Table 1). Moreover, the bacterium was isolated from lambs as young as one day old (Table 1).

A higher prevalence of $C$. perfringens was detected in younger animals, reaching a $100 \%$ prevalence in lambs less than a month old. However, the prevalence started decreasing as they grew older (> 1 month old) (Table 1). Indeed, when the lambs were two month old, the prevalence of $C$. perfringens was $67 \%$ and later started decreasing and was observed to be between $7-36 \%$ for the rest of the period (Table 1).

Based on the multiplex PCR, C. perfringens Type A was commonly isolated from the fecal samples (Table 1) [11]. However, C. perfringens type C and type D (cpe+, cpb2+) were also detected (Table 1). Both types were isolated at an age when lambs are especially susceptible to those $C$. perfringens types [8,14]. Indeed, $C$. perfringens type $C$ was isolated from newborns and C. perfringens type $\mathrm{D}(c p e+, c p b 2+)$ was isolated from lambs after weaning, when the animals were 4 month old and were moved to a new paddock. This sudden change in diet is one of the predisposing factors for enterotoxaemia caused by $C$. perfringens type D [13]. Both C. perfringens type C and type D were only isolated at one time point each and only from one animal and could not be isolated again in the following sampling time.

The genetic diversity of 19 C. perfringens isolates was analyzed by PFGE. PFGE analysis with restriction enzyme SmaI resulted in 10 different PFGE patterns (Fig. 1). All the isolates analyzed produced a fragment of approx.1,100 bp, as previously reported [20] (Fig. 1). Five C. perfringens isolates collected from eleven different animals at the same time had the same PFGE pattern (Fig. 1). In contrast, different PFGE patterns were detected in 
isolates from the same animal at different time points (Fig. 1). Indistinguishable PFGE patterns were only detected in two isolates from the same animal when weekly and not monthly samples were analyzed. The isolation of several different genetic clones of $C$. perfringens over time in the same animal could be due to the characterization of only one colony at each time point. However, when different isolates from the same animal within the same time point were analyzed, the same PFGE pattern was detected in all of them, suggesting a succession of strains in the same animal. On the basis of these results it is suggested that time may be an important factor for the isolation of clustered or even identical bacterial strains. Also, the presence of different clones isolated from the same animal at different times suggests that $C$. perfringens could pass passively through the gut because of the ingestion of spores from the environment, as previously suggested for Clostridium difficile, instead of being a permanent inhabitant of gut flora [21]. This issue remains to be further analyzed to provide new insights into the mechanism of pathogenicity and physiology of $C$. perfringens. However, care has to be taken when interpreting these results because of the small number of $C$. perfringens isolates.

\section{Acknowledgement}

We thank Macarena Bruno Galarraga, José María Garramuño, Rubén Martinez, Luciano Hernández and Martín Britos for their valuable help with animal work at the experimental farm. We are grateful to Mrs. Katja Ann Kristensen for technical assistance with PFGE analyses. In addition, we are thankful to Dr. Mariano Fernandez Miyakawa and his group for the generous supply of $C$. perfringens references strains used for the multiplex PCR. This work was supported by INTA funds under the Specific Project PNSA 1115055 
152 National Animal Health Program- Specific project: "Metabolic, toxic, infectious and

153 parasitic diseases affecting the productivity of sheep, goats and camelids".

154

155

156

157

158

159

160

161

162

163

164

165

166

167

168

169

170

171

172

\section{References}

[1] M. Sterne, I. Batty, Pathogenic Clostridia, First, Butterworth \& Co, London Boston, 1975.

[2] J.G. Songer, Clostridial enteric diseases of domestic animals, Clin. Microbiol. Rev. 9 (1996) 216-234.

[3] J.I. Rood, Virulence genes of Clostridial Perfringens, Annu. Rev. Microbiol. 52 (1998) 333-360.

[4] L. Petit, M. Gibert, M.R. Popoff, Clostridium perfringens: Toxinotype and genotype, Trends Microbiol. 7 (1999) 104-110. doi:10.1016/S0966-842X(98)01430-9.

[5] A.J.A.M. van Asten, G.N. Nikolaou, A. Gröne, The occurrence of cpb2-toxigenic Clostridium perfringens and the possible role of the $\beta 2$-toxin in enteric disease of domestic animals, wild animals and humans, Vet. J. 183 (2010) 135-140. doi:10.1016/j.tvj1.2008.11.005.

[6] A.L. Keyburn, J.D. Boyce, P. Vaz, T.L. Bannam, M.E. Ford, D. Parker, A. Di Rubbo, J.I. Rood, R.J. Moore, NetB, a new toxin that is associated with avian necrotic enteritis caused by Clostridium perfringens, PLoS Pathog. 4 (2008). doi:10.1371/journal.ppat.0040026.

[7] F.A. Uzal, J.E. Vidal, B.A. McClane, A.A. Gurjar, Clostridium perfringens toxins involved in mammalian veterinary diseases, Open Toxinology J. 3 (2010) 24-42. 
doi:10.1097/MPG.0b013e3181a15ae8.Screening.

174 [8] F.A. Uzal, J.G. Songer, Diagnosis of Clostridium perfringens intestinal infections in sheep and goats, J. Vet. Diagnostic Investig. 20 (2008) 253-265. doi:10.1177/104063870802000301.

177 [9] F.A. Uzal, Diagnosis of Clostridium perfringens intestinal infections in sheep and goats, Anaerobe. 10 (2004) 135-143. doi:10.1016/j.anaerobe.2003.08.005.

[10] G. Greco, A. Madio, D. Buonavoglia, M. Totaro, M. Corrente, V. Martella, C.

[11] R. Miserez, J. Frey, C. Buogo, S. Capaul, A. Tontis, A. Burnens, J. Nicolet, Detection of $\alpha$ - and $\varepsilon$-toxigenic Clostridium perfringens Type D in sheep and goats using a DNA amplification technique, Lett. Appl. Microbiol. 26 (1998) 382-386.

[12] W. Sipos, L. Fischer, M. Schindler, F. Schmoll, Genotyping of Clostridium perfringens isolated from domestic and exotic ruminants and swine, J. Vet. Med. Ser. B Infect. Dis. Vet. Public Heal. 50 (2003) 360-362. doi:10.1046/j.14390450.2003.00690.x.

[13] J.G. Allaart, A.J.A.M. Van Asten, A. Gröne, Predisposing factors and prevention of Clostridium perfringens-associated enteritis, Comp. Immunol. Microbiol. Infect. Dis. 36 (2013) 449-464. doi:10.1016/j.cimid.2013.05.001.

[14] K. Gkiourtzidis, J. Frey, E. Bourtzi-Hatzopoulou, N. Iliadis, K. Sarris, PCR detection and prevalence of $\alpha-, \beta-, \beta 2-, \varepsilon_{-}, t_{-}$and enterotoxin genes in Clostridium perfringens 
isolated from lambs with clostridial dysentery, Vet. Microbiol. 82 (2001) 39-43. doi:10.1016/S0378-1135(01)00327-3.

[15] A.G. Buchanan, Clinical laboratory evaluation of a reverse CAMP test for presumptive identification of Clostridium perfringens, J. Clin. Microbiol. 16 (1982) $761-762$.

[16] R.R. Meer, J.G. Songer, Multiplex polymerase chain reaction assay for genotyping Clostridium perfringens., Am. J. Vet. Res. 58 (1997) 702-705.

[17] H.S. Garmory, N. Chanter, N.P. French, D. Bueschel, J.G. Songer, R.W. Titball, Occurrence of Clostridium perfringens beta2-toxin amongst animals, determined using genotyping and subtyping PCR assays., Epidemiol. Infect. 124 (2000) 61-67. doi:10.1017/S0950268899003295.

[18] B. Nauerby, K. Pedersen, M. Madsen, Analysis by pulsed-field gel electrophoresis of the genetic diversity among Clostridium perfringens isolates from chickens, Vet. Microbiol. 94 (2003) 257-266. doi:10.1016/S0378-1135(03)00118-4.

[19] S.B. Hunter, P. Vauterin, M.A. Lambert-Fair, M.S. Van Duyne, K. Kubota, L. Graves, D. Wrigley, T. Barrett, E. Ribot, Establishment of a universal size standard strain for use with the pulsenet standardized pulsed-field gel electrophoresis protocols: Converting the national databases to the new size standard, J. Clin. Microbiol. 43 (2005) 1045-1050. doi:10.1128/JCM.43.3.1045-1050.2005.

[20] S.E. Maslanka, J.G. Kerr, G. Williams, J.M. Barbaree, L.A. Carson, J.M. Miller, B. Swaminathan, Molecular subtyping of Clostridium perfringens by pulsed-field gel electrophoresis to facilitate food-borne-disease outbreak investigations, J. Clin. 
217

218

219

220

221

222

223

224

225

226

227

228

229

230

231

232

233

Microbiol. 37 (1999) 2209-2214.

[21] A. Schoster, H.R. Staempfli, L.G. Arroyo, R.J. Reid-Smith, N. Janecko, P.E.

Shewen, J.S. Weese, Longitudinal study of Clostridium difficile and antimicrobial susceptibility of Escherichia coli in healthy horses in a community setting, Vet. Microbiol. 159 (2012) 364-370. doi:10.1016/j.vetmic.2012.04.006. 
D

D

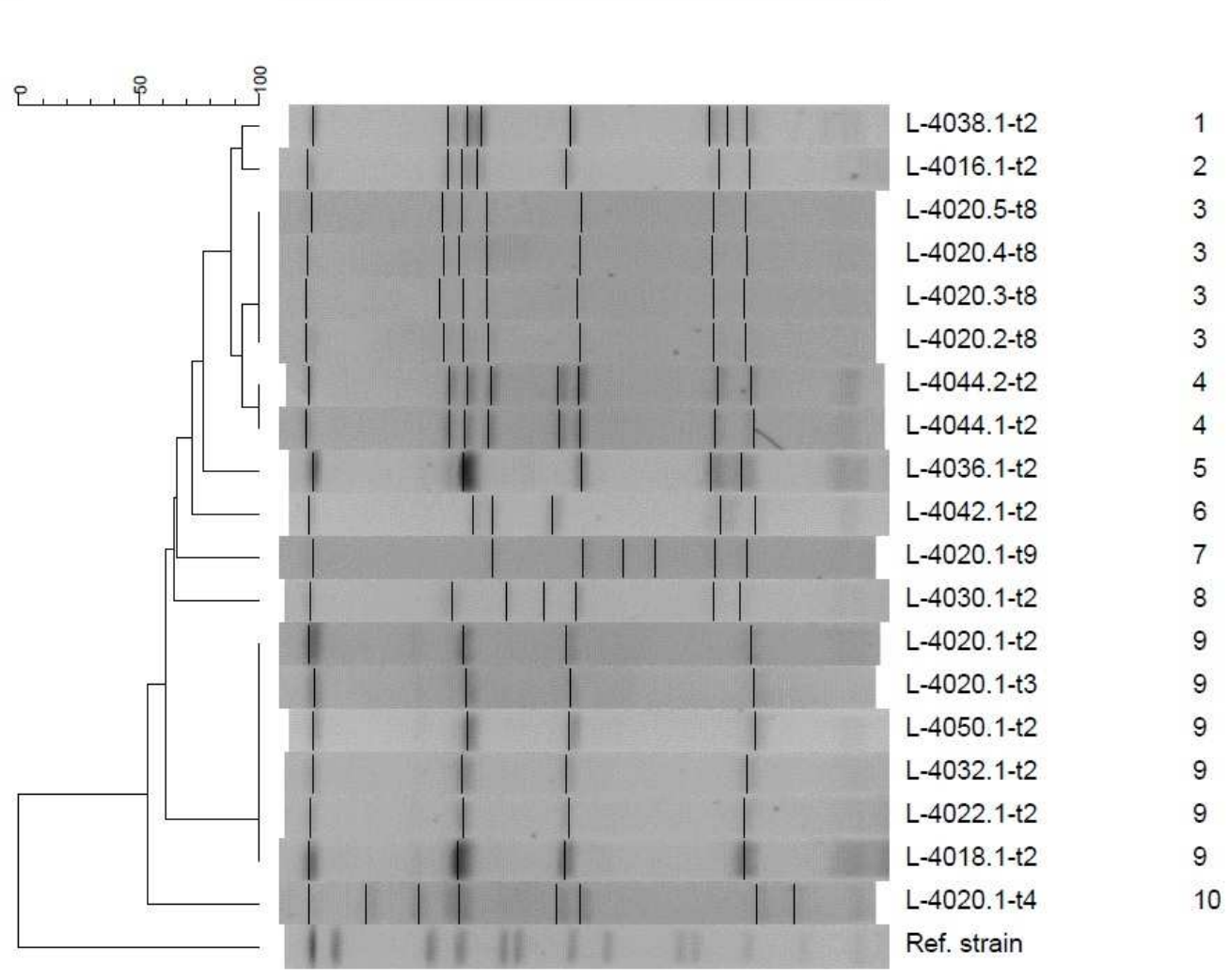

Figure 1. Dendrogram of PFGE types of $C$. perfringens isolates from healthy Merino lambs in Patagonia, Argentina. L is lamb, followed by the animal number. The different lambs samples collected at different time points ( $\mathrm{t} 2, \mathrm{t} 3, \mathrm{t} 4, \mathrm{t} 8$, and $\mathrm{t} 9)$ are shown in the left column, while the assigned PFGE patterns are shown in the right column. Ref. strain is the Salmonella serotype Braenderup H9812 reference strain. 

over time.

\begin{tabular}{|c|c|c|c|c|c|c|c|c|c|}
\hline Sample $N^{\circ}$ & 1 & 2 & 3 & 4 & 5 & 6 & 7 & 8 & 9 \\
\hline Age of lambs (days) $)^{\circ}$ & 1 & 4 & 10 & 30 & 60 & 90 & 120 & 150 & 180 \\
\hline \multicolumn{10}{|l|}{ Lamb N } \\
\hline 4016 & - & + & + & + & + & - & - & - & - \\
\hline 4018 & + & + & + & + & + & - & + & - & - \\
\hline 4020 & - & + & + & + & + & + & - & + & + \\
\hline 4022 & - & + & + & + & + & - & - & - & - \\
\hline 4026 & - & + & + & + & - & - & - & - & + \\
\hline 4030 & + & + & - & - & - & - & + & - & + \\
\hline 4032 & - & + & + & + & + & - & $+* *$ & - & + \\
\hline 4036 & + & + & + & + & - & - & 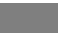 & 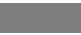 & 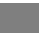 \\
\hline 4038 & - & + & + & + & - & - & - & - & - \\
\hline 4040 & + & + & + & + & - & + & + & - & + \\
\hline 4042 & - & + & + & + & + & - & + & - & - \\
\hline 4044 & - & $+*$ & + & + & + & + & - & - & - \\
\hline 4046 & - & + & + & + & + & + & - & - & - \\
\hline 4048 & & + & + & + & + & - & - & - & - \\
\hline 4050 & & + & + & + & + & - & - & - & - \\
\hline $\begin{array}{c}\% \text { of lambs } \\
\text { with } \\
\text { C. perfringens }\end{array}$ & 31 & 100 & 93 & 93 & 67 & 27 & 36 & 7 & 36 \\
\hline
\end{tabular}

average age is shown

$+C$. perfringens type $\mathrm{A}$

$+{ }^{*}$ C. perfringens type $\mathrm{A}$ and $\mathrm{C}$

$+{ }^{* *}$ C. perfringens type $\mathrm{D}($ cpe,$c p b 2)$

- negative isolation

245 